\title{
PCR primers that can detect low levels of Mycobacterium leprae DNA
}

\author{
H. D. DONOGHUE, J. HOLTON and M. SPIGELMAN \\ Department of Medical Microbiology, University College London, London W1T 4JF
}

\begin{abstract}
There are several specific PCR-based methods to detect Mycobacterium leprae DNA, but the amplicons are quite large. For example, primers that target the 36-kDa antigen gene and are in common diagnostic use yield a 530-bp product. This may be a disadvantage when examining samples in which the DNA is likely to be damaged and fragmented. Therefore, two sets of $M$. leprae-specific nested primers were designed, based on existing primer pairs which have been shown to be specific for M. leprae. Primers that targeted the 18-kDa antigen gene gave an outer product of $136 \mathrm{bp}$ and inner product of $110 \mathrm{bp}$. The primers based on the RLEP repetitive sequence yielded a 129-bp outer product and 99-bp nested product. With dilutions of a standard $M$. leprae killed whole-cell preparation as the source of DNA, both single-stage and nested PCR were performed after optimisation of the experimental conditions. Compared with the 36-kDa antigen gene primers, the 18 -kDa antigen gene outer primers were 100 -fold more sensitive and the RLEP outer primers were 1000-fold more sensitive. As an illustration of two possible applications of these new primers, positive results were obtained from three skin slit samples from treated lepromatous leprosy patients and three archaeological samples from human remains showing typical leprosy palaeopathology. It was concluded that these new primers are a useful means of detecting M. leprae DNA which is damaged or present at a very low level.
\end{abstract}

\section{Introduction}

Mycobacterium leprae, the causative agent of leprosy, is one of the few known pathogenic bacteria that cannot be cultivated in vitro. Diagnosis of the disease is based on clinical examination of the patient, histopathology and the demonstration of acid-fast bacilli in skin-slit smears or biopsies. However, the detection limit based on microscopy is c. $10^{4}$ bacilli/ml [1]. To increase the sensitivity and specificity of the detection of $M$. leprae, several authors have described methods based on PCR [2-9]. These have targeted different parts of the $M$. leprae genome and result in amplicons that are relatively large (320$530 \mathrm{bp}$ ) compared with those used routinely for the detection of M. tuberculosis (123 bp) [10].

The primers designed by Hartskeerl et al. [2] are based on the $36-\mathrm{kDa}$ antigen gene and are still used by many

Received 20 Oct. 1999; revised version accepted 12 Aug. 2000.

Corresponding author: Dr H. D. Donoghue (e-mail: h.donoghue@ucl.ac.uk). laboratories. Although the amplicon is 530-bp in size, the authors reported that their method allowed detection of a single bacterium. Williams et al. [3] used primers for the $M$. leprae $18-\mathrm{kDa}$ antigen gene that yielded a 360-bp product and could detect as few as $100 \mathrm{M}$. leprae in seeded uninfected human skin biopsy preparations. Plikaytis et al. [4] described a nested twostep PCR reaction that amplified a 578-bp outer product and 347-bp inner product from the M. leprae groEL (65-kDa antigen) gene and could detect as little as $3 \mathrm{fg}$ of DNA, which they equated with the amount found in a single bacillus. Woods and Cole [5] based their PCR on an M. leprae-specific repetitive element (RLEP), which was found by Yoon et al. [6] to be capable of detecting $M$. leprae DNA in $73 \%$ of patients with a bacterial index (BI) of 0 . This RLEP-based PCR was developed further by Santos et al. [7]. These authors optimised the DNA extraction from clinical samples and, with the inclusion of DNA hybridisation, were able to detect $100 \mathrm{ag}\left(10^{-16} \mathrm{~g}\right)$ of target DNA, equivalent to about one-tenth of the bacterial genome. The amplicon in this case was $372 \mathrm{bp}$. A nested twostage PCR based on the RLEP repetitive sequence was developed by Jamil et al. [8] with an outer product of $455 \mathrm{bp}$ and inner product of $320 \mathrm{bp}$. 
However, all these M. leprae-specific PCR methods result in amplicons which are quite large. Treated patients may continue to harbour M. leprae DNA, particularly in the case of older patients who received dapsone monotherapy [11]. Even treatment with rifampicin, which kills the organisms rapidly, results in DNA degradation over a period of 2-3 months [12] and it has been suggested that this residual DNA, possibly degraded, may play a role in late reactions [11]. Therefore, it is important that residual DNA can be detected.

DNA degrades rapidly after death and fragments over time [13]. Therefore, archaeological specimens are likely to contain fragmented DNA and c. 200 bp has been regarded as the maximum size of amplifiable mammalian DNA from ancient samples. There is increasing interest in the use of PCR to detect the presence of bacterial pathogens in human archaeological material, and both M. tuberculosis and M. leprae have been demonstrated in specimens that date from $\geqslant 1000$ years $[14,15]$.

Mycobacterial DNA is likely to be better preserved than that from other organisms, because of the hydrophobic lipid-rich cell wall. M. leprae cell walls are even thicker than those of $M$. tuberculosis, so may be anticipated to give greater protection to the microbial DNA within them. Even so, the smaller the DNA target sequence, the greater the likelihood of detecting DNA that has been damaged by antimicrobial therapy or by the passage of time.

The aim of the present study was to design primers, based on those currently in use and known to be $M$. leprae-specific, but with a smaller target sequence than those previously described, which would be suitable for use with treated leprosy patients, samples likely to contain degraded or fragmented DNA, and archaeological specimens.

\section{Materials and methods}

\section{Oligonucleotides used as PCR primers}

Eight primers were devised, which comprised outer and inner nested pairs based on the $M$. leprae-specific repetitive element (RLEP) and the M. leprae-specific $18 \mathrm{kDa}$ antigen gene. The sequences and locations of these primers are listed in Table 1. Primers LP1 and LP2 amplify a 129-bp sequence of the RLEP element, which is reported to be present at 28 copies/cell. The second set of primers, LP3 and LP4, bind internally with some overlap to LP1 and LP2, and amplify a 99bp product. Primers LP7 and LP8 amplify a 136-bp sequence of the $18-\mathrm{kDa}$ antigen gene which is present as a single copy in the M. leprae cell. The inner primers LP5 and LP6 amplify a 110-bp piece of the 136-bp product. The performance of these primers was
Table 1. Sequences of oligonucleotide primers for $M$ leprae

\begin{tabular}{lll}
\hline Primer & Residue $^{*}$ & Sequence $\left(5^{\prime}-3^{\prime}\right)$ \\
\hline LP1 & $490-509$ & TGCATGTCATGGCCTTGAGG \\
LP2 & $618-599$ & CACCGATACCAGCGGCAGAA \\
LP3 & $505-522$ & TGAGGTGTCGGCGTGGTC \\
LP4 & $603-586$ & CAGAAATGGTGCAAGGGA \\
LP5 & $622-642$ & ATCGACTGTTGTTTGCGCAAC \\
LP6 & $731-711$ & CCAGCAACCGAAATGTTCGGA \\
LP7 & $609-629$ & TCATAGATGCCTAATCGACTG \\
LP8 & $744-726$ & GGCACATCTGCGGCCAGCA \\
\hline
\end{tabular}

${ }^{*}$ For primers LP1-LP4 the primer sequence is found in the $M$. leprae RELP3 sequence X17153. For primers LP5-LP8 the primer sequence is found in the M. leprae $18-\mathrm{kDa}$ antigen gene sequence MSGANT18K.

compared with the $36-\mathrm{kDa}$ antigen gene primers S13 and S62 [2].

\section{Skin-slit samples}

Fresh skin-slit samples were obtained from two patients from the Sanatorio San Francisco de Borja in Fontilles, Spain and stored at $-20^{\circ} \mathrm{C}$ until use. The patients had initially been diagnosed as having lepromatous leprosy 20-30 years previously. One patient (B1) had been treated with the recommended WHO regimen for 6 months. The second had received dapsone monotherapy 10 years earlier and returned to the hospital with a reversal reaction. One sample was taken at this time (B2) and another (B3) after the completion of the recommended WHO regimen of rifampicin, clofazimine and dapsone for 6 months and steroids $20-30 \mathrm{mg} /$ day. The samples were supplied by the Pathology Laboratory of the Sanatorio San Francisco de Borja, and stated as having a BI of zero.

\section{Archaeological samples}

Six archaeological samples were examined. Samples A1 and A2 were obtained from a putative case of leprosy from a mediaeval burial ground in Suraz, Poland. This was the body of a 40-50-year-old male with characteristic changes in the nose on X-ray and in the leg and toe bones. Samples of this specimen were examined from two areas - around the nasal region (A1) and the metatarsals (A2) [16]. Samples A3 and A4 were from a 10-11th century site at Püspövladány, Hungary, and both samples were from cavum nasale with periostitis. Samples A5, a metatarsus ('pencil' form), and A6, a fibula, were from a grave in a 1415th century site at Ópusztaszer-Monostor, Hungary.

\section{DNA extraction}

The method was essentially the second protocol described by Donoghue et al. [14]. Briefly, c. $25 \mathrm{mg}$ of crushed sample were pre-incubated in proteinase $\mathrm{K} /$ EDTA, treated with lysis buffer L6 [17] based on guanidium thiocyanate/EDTA/Triton X-100, mixed on a bead beater and the DNA was captured on to silica. 
The silica was washed with washing buffer L2 [17], ethanol $70 \%$ and acetone, dried and the DNA was eluted by incubation at $65^{\circ} \mathrm{C}$. Preparations were stored at $-20^{\circ} \mathrm{C}$ until used. The silica supernates were also processed. These were chilled on ice and $200 \mu \mathrm{l}$ of Protein Precipitation Solution (Puregene ${ }^{\circledR}$ Flowgen Instruments, Lichfield) were added to each tube. Tubes were vortex mixed for at least $20 \mathrm{~s}$, then centrifuged for $3 \mathrm{~min}$. To precipitate DNA, the supernates were added to $600 \mu \mathrm{l}$ of isopropanol $\left(-20^{\circ} \mathrm{C}\right)$ in clean, sterile tubes, mixed by inversion 50 times and then centrifuged for $3 \mathrm{~min}$. After discarding the supernates, tubes were drained on clean, absorbent paper, then washed once with $600 \mu \mathrm{l}$ of ethanol $70 \%\left(-20^{\circ} \mathrm{C}\right)$. Tubes were drained once again and dried with loosened lids in a $56^{\circ} \mathrm{C}$ heating block for $2 \mathrm{~h}$. DNA was rehydrated in $100 \mu \mathrm{l}$ of water by placing tubes in a water bath at $65^{\circ} \mathrm{C}$ for $1 \mathrm{~h}$. Preparations were mixed and centrifuged briefly, divided into small volumes and stored at $-20^{\circ} \mathrm{C}$ until used.

\section{Bacterial cell suspension}

The source of M. leprae DNA was the reagent known as lepromin, which consists of an autoclaved suspension of bacilli extracted from armadillo tissues, which is used for skin testing in epidemiological studies. This is supplied with an estimated bacterial load of $6 \times 10^{9}$ organisms $/ \mathrm{ml}$ and was supplied by Dr M. J. Colston (National Institute for Medical Research, London). The suspension was divided into small volumes and stored at $-20^{\circ} \mathrm{C}$ until used. Serial 10 -fold dilutions were prepared with sterile water (Sigma-Aldrich) immediately before use.

\section{PCR amplification}

Stringent precautions were necessary to avoid crosscontamination. Clean protective clothing was worn with frequent glove changes. A separate room was used for handling PCR product, with a different set of pipettors and protective clothing. Pipettors and surfaces were cleaned with neat household liquid detergent, rinsed with ultrapure water and dried with ethanol before use. Sterile tubes and plugged tips were used.

Pre-aliquoted double-strength PCR mix was purchased from (Advanced Biotechnologies, Epsom). The final composition of the PCR mixture $(50 \mu \mathrm{l})$ was $75 \mathrm{mmol}$ Tris-HCI (pH 8.8); $20 \mathrm{mmol}\left(\mathrm{NH}_{4}\right)_{2} \mathrm{SO}_{4} ; 1.5 \mathrm{mmol}$ $\mathrm{MgCl}_{2}$; Tween $200.01 \% \mathrm{v} / \mathrm{v} ; 200 \mu \mathrm{mol}$ (each) dATP, dCTP, dGTP and dTTP; and 1.25 units Taq DNA polymerase. Bovine serum albumin was added to give a final concentration of $10 \mathrm{mM}$ as this has been shown to improve the yield [18]. The primer pair and DNA preparation $(5.0 \mu \mathrm{l})$ were added to each pre-aliquoted tube plus sufficient water to bring the volume to $50 \mu \mathrm{l}$. A tube with water in place of template was always included as a negative control. Primers were used at final concentrations as follows: LP1, LP2, LP3 and
LP4, $60 \mathrm{nM}$; LP5 and LP6, $100 \mathrm{nM}$; LP7 and LP8, $200 \mathrm{nM} ; \mathrm{S} 13$ and S62, $1.0 \mu \mathrm{M}$ initially, then $100 \mathrm{nM}$.

\section{Single-stage PCR to detect M. leprae DNA}

Amplification consisted of one cycle of denaturation at $95^{\circ} \mathrm{C}$ for $5 \mathrm{~min}$, primer annealing at $58^{\circ} \mathrm{C}$ (RLEP primers) or $55^{\circ} \mathrm{C}$ for $2 \mathrm{~min}$, and DNA extension at $72^{\circ} \mathrm{C}$ for $2 \mathrm{~min}$. This was followed by $35-45$ cycles of $30 \mathrm{~s}$ at $94^{\circ} \mathrm{C}, 30 \mathrm{~s}$ at $58^{\circ} \mathrm{C}$ or $55^{\circ} \mathrm{C}$ and $1 \mathrm{~min}$ at $72^{\circ} \mathrm{C}$, followed by $10 \mathrm{~min}$ at $72^{\circ} \mathrm{C}$.

\section{Nested PCR to detect M. leprae DNA}

A two-tube procedure was used. In the first stage, the outer primers (LP1/LP2 or LP7/LP8) were added to the PCR mix. Amplification was performed as follows. After strand separation at $94^{\circ} \mathrm{C}$ for 4 min there were 25 amplification cycles of $94^{\circ} \mathrm{C}$ for $40 \mathrm{~s}$, annealing at $55^{\circ} \mathrm{C}$ or $58^{\circ} \mathrm{C}$ for $1 \mathrm{~min}$, then strand extension at $72^{\circ} \mathrm{C}$ for $20 \mathrm{~s}+1 \mathrm{~s}$ increment per cycle. Finally, there was $1 \mathrm{~min}$ at $72^{\circ} \mathrm{C}$ for further strand extension. New tubes of PCR mix were used in the second stage of nested PCR. The inner primers (LP3/LP4 or LP5/LP6) were transferred into each reaction tube, together with $0.5 \mu \mathrm{l}$ of product which was used as the DNA template. The total volume was made up to $50 \mu \mathrm{l}$ with sterile water. This second stage PCR cycle was identical to the first.

\section{Gel electrophoresis}

PCR product $(8 \mu \mathrm{l})$ was added to loading buffer (Sigma) $2.5 \mu \mathrm{l}$ and electrophoresed in a NuSieve 3:1 agarose $3.0 \%(\mathrm{w} / \mathrm{v})$ gel (FMC Bioproducts, Flowgen) in TBE buffer $(0.09 \mathrm{M}$ Tris-borate and $0.002 \mathrm{M}$ EDTA $)$ at $8.8 \mathrm{~V} \mathrm{~cm}$ for $80 \mathrm{~min}$. Amplified DNA was visualised by ethidium bromide staining plus ultraviolet light and was recorded with a Polaroid camera.

\section{DNA sequencing}

PCR product was either sequenced directly or was first separated from other components in the reaction mixture by separation on a gel as above, by electrophoresis with TAE buffer $(0.04 \mathrm{M}$ Tris-acetate and $0.001 \mathrm{M}$ EDTA.) The selected band $(150-250 \mathrm{mg})$ was removed from the gel with a sterile scalpel blade into a sterile 0.5-ml tube. DNA was extracted from the gel slices with a MERmaid ${ }^{\mathrm{TM}}$ Spin Kit (10-200 nucleotides) (Anachem, Luton). The purified DNA was then sequenced by MWG-BIOTECH GmbH or by an inhouse sequencing service in the UCL Department of Biological Sciences.

\section{Results}

Single-stage PCR to detect M. leprae-specific DNA

The new primers and primers S13/S62 were tested against 10-fold dilutions of the lepromin reagent. 
Initially, an annealing temperature of $58^{\circ} \mathrm{C}$ was used. The untreated lepromin reagent gave a good yield of M. leprae DNA (Fig. 1). The outer RLEP primers LP1/LP2 gave a strong band of the 129-bp product with a $1 \times 10^{4}$ dilution of lepromin. The inner RLEP primers LP3/LP4 and S13/S62 gave weak bands at this dilution. The outer $18-\mathrm{kDa}$ antigen primers LP7/LP8, which had been used at $100 \mathrm{nM}$, gave little product under these conditions, although the inner primers LP5/LP6 gave only slightly less product at a $1 \times 10^{4}$ dilution than LP1/LP2. Optimisation experiments showed that best results were obtained with $200 \mathrm{mM} \mathrm{LP7}$ and LP8, and and annealing temperature of $55^{\circ} \mathrm{C}$. The lower annealing temperature also improved the yield of the LP5/LP6 product.

When 45 cycles of amplification were used, a positive result was obtained from a $1 \times 10^{8}$ dilution of $M$.

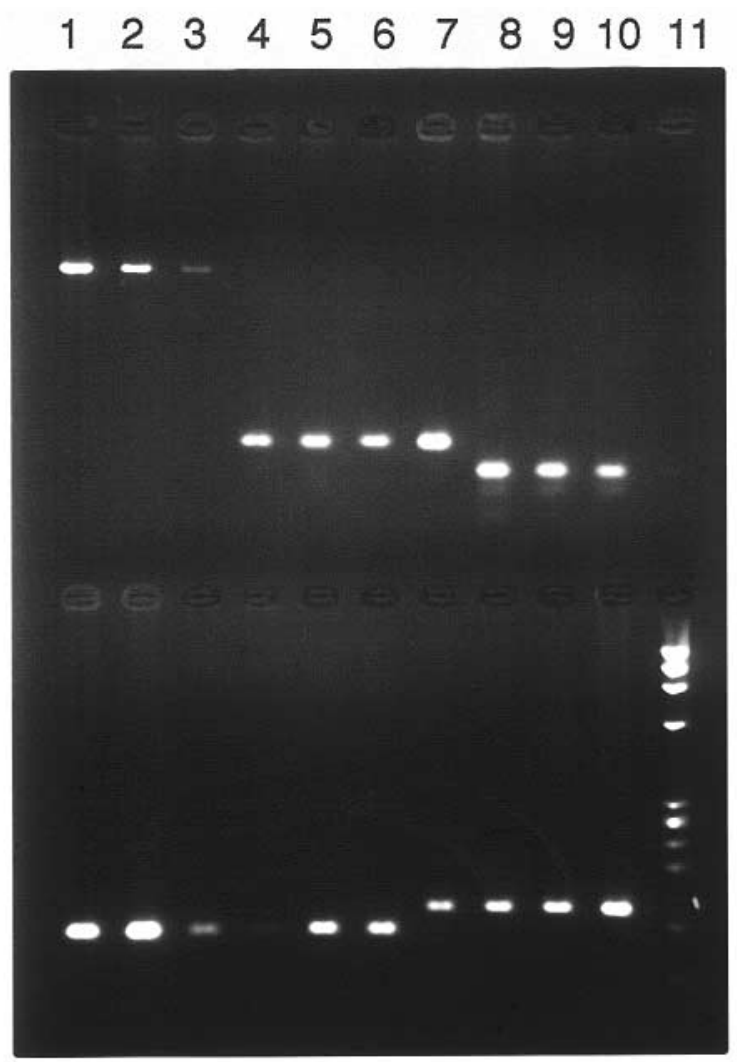

Fig. 1. M. leprae PCR after 35 cycles of amplification with different primer pairs and $M$. leprae dilutions from $1 \times 10^{1}$ to $1 \times 10^{4}$. The annealing temperature was $58^{\circ} \mathrm{C}$ unless otherwise indicated. Top row, lanes $\mathbf{1 - 3}$, primers $\mathrm{S} 13 / \mathrm{S} 62$ for $530-\mathrm{bp}$ product from $32-\mathrm{kDa}$ antigen gene, dilutions $10^{2}, 10^{3}, 10^{4} ; 4-7$, primers LP1/LP2 for 129 -bp product from RLEP sequence, dilutions $10^{1}, 10^{2}, 10^{3}$, $10^{4} ; 8-11$, primers LP3/LP4 for 99-bp product from RLEP sequence, dilutions $10^{1}, 10^{2}, 10^{3}, 10^{4}$. Bottom row, lanes 1-4, primers LP5/LP6 for 110-bp product from 18$\mathrm{kDa}$ antigen gene, dilutions $10^{1}, 10^{2}, 10^{3}, 10^{4} ; 5-6$, primers LP5/LP6 for $110-\mathrm{bp}$ product from $18-\mathrm{kDa}$ antigen gene dilutions, $10^{3}, 10^{4}$, with annealing at $55^{\circ} \mathrm{C}$; 7-10, primers LP7/LP8 for 136-bp product from 18-kDa antigen gene, dilutions $10^{1}, 10^{2}, 10^{3}, 10^{4}$ with annealing at $55^{\circ} \mathrm{C} ; 11, \Phi X 174$ Hae III digest molecular markers. leprae with primers LP1/LP2. The end-point with LP7/LP8 was 10 -fold less and for primers S13/S62; $1 \times 10^{5}$ was the highest dilution that gave visible product.

\section{Use of nested PCR to detect M. leprae DNA from clinical and archaeological samples}

After nested PCR with the $18-\mathrm{kDa}$ antigen gene primers a band of the expected size $(110 \mathrm{bp})$ was visible from archaeological samples A1, A3 and A4 (Fig. 2). These archaeological samples were also positive with the RLEP primers. One archaeological sample, A3, yielded more product than a $1 \times 10^{4}$ dilution of $M$. leprae DNA. There was no product from samples A2, A5 or A6, a DNA extraction control, nor from the PCR negative control. Sample B1 from a treated lepromatous leprosy patient was positive with both the RLEP and $18-\mathrm{kDa}$ antigen gene primers. The first sample from the patient with a reversal reaction (B2) was negative with the $18-\mathrm{kDa}$ antigen primers, but positive when the RLEP primers were used. Sample B3, obtained immediately after completion of the

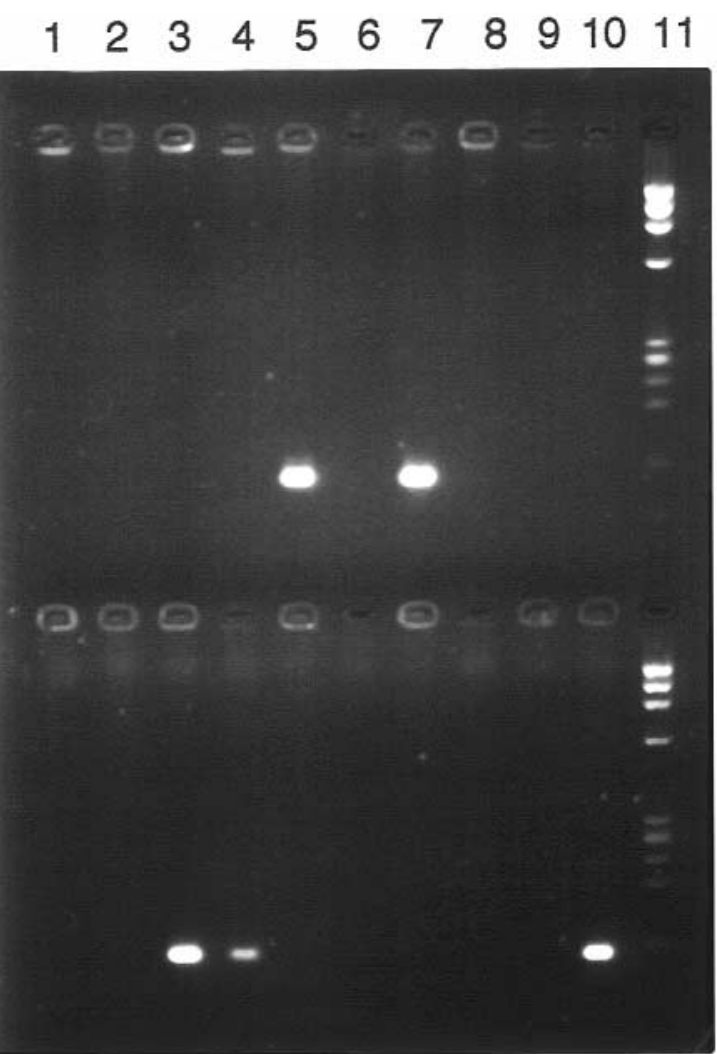

Fig. 2. Nested PCR for $M$. leprae with $18-\mathrm{kDa}$ antigen gene primers. Top row, lane 1, B2 (silica eluate); 2, B2 (silica supernate); 3-4, other negative samples; 5, A1 (eluate); 6, A1 (supernate); 7, A3 (eluate); 8, A3 (supernate); 9-10, other negative samples; 11, ФX174Hae III digest molecular markers. Bottom row, lanes 1-2, other negative samples; 3 A4 (eluate); 4, A4 (supernate): 5-6, other negative samples; 7, extraction control (eluate); 8, extraction control (supernate); 9, PCR control; 10, $M$. leprae $1 \times 10^{4}$ dilution; 11, ФX174Hae III digest molecular markers. 
WHO treatment regimen, gave a very weak positive result, but only with the RLEP primers.

\section{Use of single-stage PCR to detect M. leprae DNA in clinical and archaeological samples}

After 45 cycles of amplification, no positive results were obtained with either RLEP or $18-\mathrm{kDa}$ antigen primers from the treated lepromatous patient samples B1, B2 or B3. However, archaeological samples A1, A3 and A4 yielded products of the expected size with primers LP1/LP2 and LP7/LP8, and appeared to be of equivalent strength to a $1 \times 10^{4}$ dilution of M. leprae.

\section{DNA sequencing}

With the RLEP outer primers LP1 and LP2, a complete sequence of 129 bases was obtained from archaeological sample A4: TGCATGTCATGGCCTTGAGGTGTC GGCGTGGTCAATGTGGCCGCACCTGAACAGGCA CGTCCCCGTGCACGGTATAACTATTCGCACCTGA TGTTATCCCTTGCACCATTTCTGCCGCTGGTATCG GTG. This identical sequence is found in 30 sequences of $M$. leprae held in the gene data bank. With the exception of an internal 18-bp sequence, a BLAST search of the gene database held by the National Center for Biotechnology Information showed that this product is unique to $M$. leprae.

With the inner RLEP primers LP3 and LP4, a provisional 81-bp sequence was obtained from archaeological sample A3: CCGCACCTGAACAGGCACGTC CCCGTGCACGGTATAACTATTCG-ACCTGATGTTA TCCCTTGCACCATTTCTGNCGCTGG. Where the sequence was obtained from both primers it was identical to that in the database. However, part of the sequence was obtained from only one primer and contained a missing value (-) and one indeterminate result $(\mathrm{N})$.

Preliminary results were also obtained with primer LP8 for the $18-\mathrm{kDa}$ antigen gene and a 108-bp sequence was obtained from the archaeological sample A1: TGTTCNGATACTTTAAAGATCCATGGCTAAGACG GGCTTTTGACCGCAGCGGCGTGCTTAGCTTCGTG CTTAGCTTGTTGCGCAAACAACAGTCGATTAGGC ATCTAT. There is one undetermined base $(\mathrm{N})$, but otherwise this sequence has $100 \%$ similarity with two sequences of $M$. leprae held in the databank. There is overlap with the primers LP7 and LP8 and the whole length of the intervening DNA has been sequenced.

With the inner primers LP5 and LP6, a 110-bp complete sequence was obtained from the archaeological sample A3 which is identical to the $M$. leprae sequence in the database: ATCGACTGTT GTTTGCGCAACAAGCTAAGCACGAAGCTAAGCA CGCCGCTGCGGTCAAAAGCCCGTCTTAGCCATG GATCTTTAAAGTATCCGAACATTTCGGTTGCTGG. A BLAST nucleotide search revealed that, with the exception of an internal 18-bp sequence, both these
$18-\mathrm{kDa}$ antigen gene sequences are unique to $M$. leprae.

\section{Discussion}

Two nested pairs of primers were used to successfully amplify $M$. leprae DNA from the lepromin skin test reagent, samples from treated leprosy patients with a BI of zero, and from three of six archaeological specimens dating from the 10 th -11 th centuries. Nested PCR increases the sensitivity of PCR as it enables a total of 50 amplification cycles to be used, but avoids over-amplification artefacts. It was only with nested PCR based on the RLEP primers that all three clinical samples were found to give positive results. It is not known whether or not residual $M$. leprae DNA is of any clinical significance, so it may be of interest to use these primers, which can detect lower amounts of $M$. leprae DNA than current methods permit, in longitudinal studies of treated leprosy patients.

All three positive archaeological samples were obtained from the cavum nasale. It is known that M. leprae localises to Schwann cells and nasal epithelial cells [19], and that this can result in an overwhelming rhinitis associated with very high numbers of the organism. The three cavum nasale specimens demonstrated the typical palaeopathology associated with leprosy, so it was likely that $M$. leprae DNA was in these samples at the time of death of the host. The detection of $M$. leprae in specimens $>1000$ years old was described previously in a preliminary report [15] and these additional observations, plus DNA sequencing data, confirm the persistence of $M$. leprae DNA. Leprosy is primarily a disease of peripheral nerves and skin, but affects bones as well. However, the absence of detectable $M$. leprae DNA in the metatarsal specimens (A2, A5) and the fibula sample (A6) need not imply that the remains were from individuals who were not suffering from the disease. Although many skeletons have been found with changes associated with lepromatous leprosy, the peripheral bones are likely to contain relatively little $M$. leprae DNA compared with the nasal region. Furthermore, most observers consider the changes in the limbs to be due to secondary infection, which is the result of loss of sensation due to nerve damage by the organism [20], so some affected limbs may contain no M. leprae DNA at all.

All the new primers were of greater sensitivity than the commonly used primers described by Hartskeerl et al. [2] and enabled the M. leprae-positive archaeological specimens to be detected by single-stage in addition to nested PCR. One reason for this difference is the smaller target size, as this is more likely to result in successful PCR assay of damaged and fragmented DNA. The most sensitive primers were based on the repetitive sequence (RLEP), which is repeated 28 times in the $M$. leprae chromosome. The primers based on 
the $18-\mathrm{kDa}$ antigen gene, present as a single copy per cell, were $c$. 10 times less sensitive, whereas the Hartskeerl primers, which result in a 530-bp product, were 1000-fold less sensitive. The lepromin reagent contains $c .10^{9}$ organisms $/ \mathrm{ml}$, but it is not known if all the DNA is available for amplification. Therefore, it is calculated that primers LP1/LP2, in a single-stage PCR with 45 amplification cycles, detected at least 0.3 of an organism, and it is very likely that the sensitivity is still greater.

It was concluded that these newly described primers have greater sensitivity in detecting $M$. leprae DNA in samples where the quantity and quality of the residual DNA is likely to be low. Appropriate applications for these primers may be longitudinal studies of treated leprosy patients, and palaeopathological investigations.

We thank Dr M. J. Colston (National Institute for Medical Research, London) who supplied the lepromin skin test reagent as a source of M. leprae. Clinical samples were supplied by Dr Pedro Torres, director, Pathology Laboratory, Sanatorio San Francisco de Borja, Fontilles, Spain. Archaeological specimens were provided by professor Judyta Glladykowska-Ryyeczyzka (Department of Anatomy and Anthropology, Academy of Physical Education, Gdansk, Poland) and Dr Antónia Marcik (Department of Anthropology, Josef Attila University, Szeged, Hungary). J. H. and M. S. acknowledge funding from the Wellcome Trust, for support in the archaeological studies This work was reported briefly at the International Congress on The Past and Present of Leprosy, 26-31 July 1999, in Bradford, UK.

\section{References}

1. Shepard CC, McRae DH. A method for counting acid-fast bacteria. Int J Lepr 1968; 36: 78-82.

2. Hartskeerl RA, De Wit MYL, Klatser PR. Polymerase chain reaction for the detection of Mycobacterium leprae. J Gen Microbiol 1989; 135: 2357-2364.

3. Williams DL, Gillis TP, Booth RJ, Looker D, Watson JD. The use of a specific DNA probe and polymerase chain reaction for the detection of Mycobacterium leprae. J Infect Dis 1990; 162: 193-200.

4. Plikaytis BB, Gelber RH, Shinnick TM. Rapid and sensitive detection of Mycobacterium leprae using a nested-primer gene amplification assay. J Clin Microbiol 1990; 28: 1913-1927.

5. Woods SA, Cole ST. A rapid method for the detection of potentially viable Mycobacterium leprae in human biopsies: a novel application of PCR. FEMS Microbiol Lett 1989; 53: 305-309.

6. Yoon D-H, Cho S-N, Lee M-K et al. Evaluation of polymerase chain reaction amplification of Mycobacterium leprae-specific repetitive sequence in biopsy specimens from leprosy patients. J Clin Microbiol 1993; 31: 895-899.

7. Santos AR, De Miranda AB, Sarno EN, Suffys PN, Degrave WM. Use of PCR-mediated amplification of Mycobacterium leprae DNA in different types of clinical samples for the diagnosis of leprosy. J Med Microbiol 1993; 39: 298-304.

8. Jamil S, Wilson SM, Hacket M, Hussein R, Stoker NG. A colorimetric PCR method for the detection of M. leprae in skin biopsies from leprosy patients. Int J Lepr 1994; 62: 512520 .

9. Scollard DM, Gillis TP, Williams DL. Polymerase chain reaction assay for the detection and identification of $\mathrm{Myco}$ bacterium leprae in patients in the United States. Am J Clin Pathol 1998; 109: 642-646.

10. Eisenach KD, Cave MD, Bates JH, Crawford JT. Polymerase chain reaction amplification of a repetitive DNA sequence specific for Mycobacterium tuberculosis. J Infect Dis 1990; 161: $977-981$.

11. Rafi A, Donoghue HD, Stanford JL. Application of polymerase chain reaction for the detection of Mycobacterium leprae DNA in specimens from treated leprosy patients. Int J Lepr 1995; 63: $42-47$.

12. Fiallo P, Willams DL, Chan GP, Gillis TP. Effects of fixation on polymerase chain reaction detection of Mycobacterium leprae. J Clin Microbiol 1992; 30: 3095-3098.

13. Hagelberg E, Sykes B. Ancient bone DNA amplified. Nature 1989; 342: 485.

14. Donoghue HD, Spigelman M, Zias J, Gernaey-Child AM, Minnikin DE. Mycobacterium tuberculosis conplex DNA in calcified pleura from remains 1400 years old. Lett Appl Microbiol 1998; 27: 265-269.

15. Rafi A, Spigelman M, Stanford J, Lemma E, Donoghue H, Zias J. DNA of Mycobacterium leprae detected by PCR in ancient bone. Int J Osteoarchaeol 1994; 4: 287-290.

16. Glladykowska-Rzeczycka J. A case of leprosy from a medieval burial ground. Folion Morphol Warsz 1976; 35: 253-264.

17. Boom R, Sol CJA, Salimans MMM, Jansen CL, Wertheim-van Dillen PME, van der Noordaa J. Rapid and simple method for purification of nucleic acids. J Clin Microbiol 1990; 28: 495-503.

18. Forbes BA, Hicks KE. Substances interfering with direct detection of Mycobacterium tuberculosis in clinical specimens by PCR: effects of bovine serum albumin. J Clin Microbiol 1996; 34: 2125-2128.

19. Andersen JG, Manchester K. The rhinomaxillary syndrome in leprosy: a clinical, radiological and palaeopathological study. Int J Osteoarchaeol 1992; 2: 121-129.

20. Møller-Christensen V. Bone changes in leprosy. Copenhagen, Munksgaard. 1961: 42-43. 